\title{
Construction Tender Subcontract Selection using case-based reasoning
}

Due Thanh Luu (Quasar Group of Constructions Pty Ltd, Australia) and Wily Sher (School of Architecture and Built Environment, University of Newcastle, Newcastle, Australia)

\section{ABSTRACT}

Obtaining competitive quotations from suitably qualified subcontractors at tender tim $\mathbf{n}$ significantly increase the chance of w1nmng a construction project. Amidst an increasingly growing trend to subcontracting in Australia, selecting appropriate subcontractors for a construction project can be a daunting task requiring the analysis of complex and dynamic criteria such as past performance, suitable experience, track record of competitive pricing, financial stability and so on. Subcontractor selection is plagued with uncertainty and vagueness and these conditions are difficult $\mathbf{O}$ represent in generalised sets of rules. DecisıOns pertaining to the selection of subcontr:act?s tender time are usually based on the mtu1t1on and past experience of construction estimators. Case-based reasoning (CBR) may be an appropriate method of addressing the chal_lenges of selecting subcontractors because CBR 1 s able to harness the experiential knowledge of practitioners. This paper reviews the practicality and suitability of a CBR approach for subcontractor tender selection through the development of a prototype CBR procurement advisory system. In this system, subcontractor selection cases are represented by a set of attributes elicited from experienced construction estimators. The results indicate that CBR can enhance the appropriateness of the selection of subcontractors for construction projects.

Key words: Construction estimating, subcontractor selection, case-based reasomng.

\section{INTRODUCTION}

Subcontracting is a long-established practice in the construction industry and provides an essential element of flexibility in the overall construction supply chain. Appropriate use of subcontractors facilitates the execution of works in a cost-effective manner with efficient use of resources. On the other hand, unproductive subcontracting, incorporating such characteristics as multi-layer subcontracting, broker-type subcontracting or "fly-by-night" subcontracting, may have adverse impact on the progress and quality of construction works (Tang, H. 2001).

Generally, building contractors only act as construction management agents in construction projects, subletting a significant proportion (about 90\%) of construction works to subcontractors (Shash, 1999). In competitive tendering, construction estimators rely largely on subcontractor"s sub-bids to arrive at a final tender sum to be submitted to clients. As the lowest tender is a determinant factor is securing work in traditional competitive tendering environments (Tam, 2003), estimators often need to choose appropriate tender subcontractors who not only offer competitive prices that contribute to main contractors" chances of winning tenders but who also perform well during actual construction of projects. The selection of tender subcontractors therefore needs to be based on a combined assessment of a variety of criteria including past performance, suitable experience, track record of competitive pricing, financial stability, and so on. This assessment is usually based upon intuition and past experience. Set amidst a large and changing number of subcontractors and a short tender period, this activity can be challenging, especially for inexperienced estimators.

It is pertinent to note that commercially available computer-aided estimating systems currently provide limited assistance to esti_mat rs area. The facilities that are prov1ded mclude repositories of sub-contractor details and performance indicators, and adjudication tools that assist estimators in selecting quotes for a 
particular tender. The provision of facilities such as those described in this paper therefore provides valuable assistance to estimators.

A method of addressing this situation is to draw on solutions to previous similar problems (Kolodner, 1993). Case-based reasoning (CBR) is a computer-assisted approach that draws on repositories of outcomes of such experiences. Aamodt and Plaza (1994) describe CBR as a paradigm that is similar to the way human beings adapt when solving problems.

In this paper, the processes involved in selecting suitable construction tender subcontractors are first scrutinised and a conceptual CBR framework that mimics these processes is then proposed. The design of a prototype Casebased System for Selecting suitable Subcontractors (CASSS) is then described. The practicality of the prototype is illustrated through an example of a construction tender.

\section{THE SUBCONTRACTOR SELECTION PROCESS}

To confirm the mechanisms of subcontractor selection in Australia, six interviews were conducted with estimators employed by major and medium sized building contractors. These sources established that estimators normally select tender subcontractors based on those used on previous similar successful tender(s). Estimators were found to use a number of factors to establish similarity including: characteristics of proposed construction projects; the market conditions where the project would take place; as well as main contractors' expectations of potential subcontractors. Table 1 outlines these factors.

\begin{tabular}{|c|c|}
\hline Similarity Parameters & Possible Values \\
\hline \multicolumn{2}{|l|}{ Project related } \\
\hline Project Category & $\begin{array}{l}\text { Administrative and civic; commercial; educational; hospital; } \\
\text { industrid recreational; residential; civil engineering; others }\end{array}$ \\
\hline Construction type & New construction; refurbishment; combination of both \\
\hline Size & $<\$ 0.3 \mathrm{M} ;$ \$0.3M-\$0.5M; \$0.5M-\$3M; \$3M-\$20M; > \$20M \\
\hline Location & $\begin{array}{l}\text { Sydney; Wollongong and Illawara region; Newcastle and } \\
\text { Hunter valley region; Mid North Coast; North Coast; North } \\
\text { West NSW; South West NSW }\end{array}$ \\
\hline Complexity & High, medium, low \\
\hline Procurement type & $\begin{array}{l}\text { Construct only; Design \& construct; } \quad \text { Construction } \\
\text { Management; Management Contracting }\end{array}$ \\
\hline \multicolumn{2}{|l|}{ Subcontractor's related } \\
\hline $\begin{array}{l}\text { Suitable experience relevant to } \\
\text { current type of project }\end{array}$ & High, medium, low \\
\hline Track record of competitive pricing & Always competitive; average; not competitive \\
\hline $\begin{array}{l}\text { Track record of performance during } \\
\text { construction }\end{array}$ & Outstanding; average; poor \\
\hline Financial stability & High, medium. Iow \\
\hline $\begin{array}{lll}\text { Availability } & \text { of } & \text { suitable } \\
\text { subcontractors } & & \end{array}$ & High, medium, low \\
\hline $\begin{array}{l}\text { Current dispute with main } \\
\text { contractor }\end{array}$ & Yes; No \\
\hline
\end{tabular}


In addition to consulting databases of subcontractors used on previous similar tenders, estimators were influenced by how competitive their tenders were. Estimators reviewed selected sub-sets of subcontractors to determine their suitability for the current tender by comparing them to the nominal 'best' subcontractor of the same trade category (e.g. mechanical , electrical, hydraulic, structuralsteel, etc.). A subcontractor was considered the best for a particular project if it could be established that they could potentially submit a highly competitive sub-bid. If the tender is won, the subcontractor needs to be able to complete the subcontract in a technically sound and proficient, financially secure and occupationally healthy and safe manner. The process in which the estimators selected subcontractors for their tenders is described in Figure 1.
Identify characteristics of tender projeels and criteria for selecting suitable subcontrcictors
Similarity of current

situation \& degree of success of past tenders

Appropriateness of each

Retrieve solution(s) of

the most sirrular projeels

Select the most suitable subcontractors

Figure 1: Process of Selecting Subcontractors for Tendering

\section{FRAMEWORK FOR THE CBR SUB-} CONTRACTOR SELECTION MODEL

CBR can be beneficially used to support the tender subcontract selection process described above. A conceptual framework that drives the development of a case-based subcontractor selection advisory system is shown in Figure 2. The framework consists of three key modules, i.e. input, selection, and output.

The Input module provides construction estimators with a means of submitting data. Estimators need to enter similarity parameters for construction tenders and rate their importance. Depending on these similarity parameters and their weightings, similar ses are retrieved by the Subcontractor Select1on module. These similar cases are accumulated over time as the system is used on successive occasions. It therefore follows that the more the system is used the more accurate it becomes. The retrieval process is performed using a nearest neighbour retrieval mechanism (Kolodner, 1993). A list of subcontractors used in similar past tenders and the degree of success of those tenders is provided to estimators for consideration. When data comparable to the current case has been selected, and estimators have found the solution and outcome to be 
tender project. If suitable case data are not available, estimators will need to adapt data to suit the distinctive characteristics of the new tender. Further details on this process are provided in the next section.
The selected subcontractors are then reported to estimators through the output module. All data (including the project similarity parameters and their importance weightings) are presented for checking. Details of the new case and the adopted or adapted solution(s) are stored in the CBR database for future reference and retrieval.

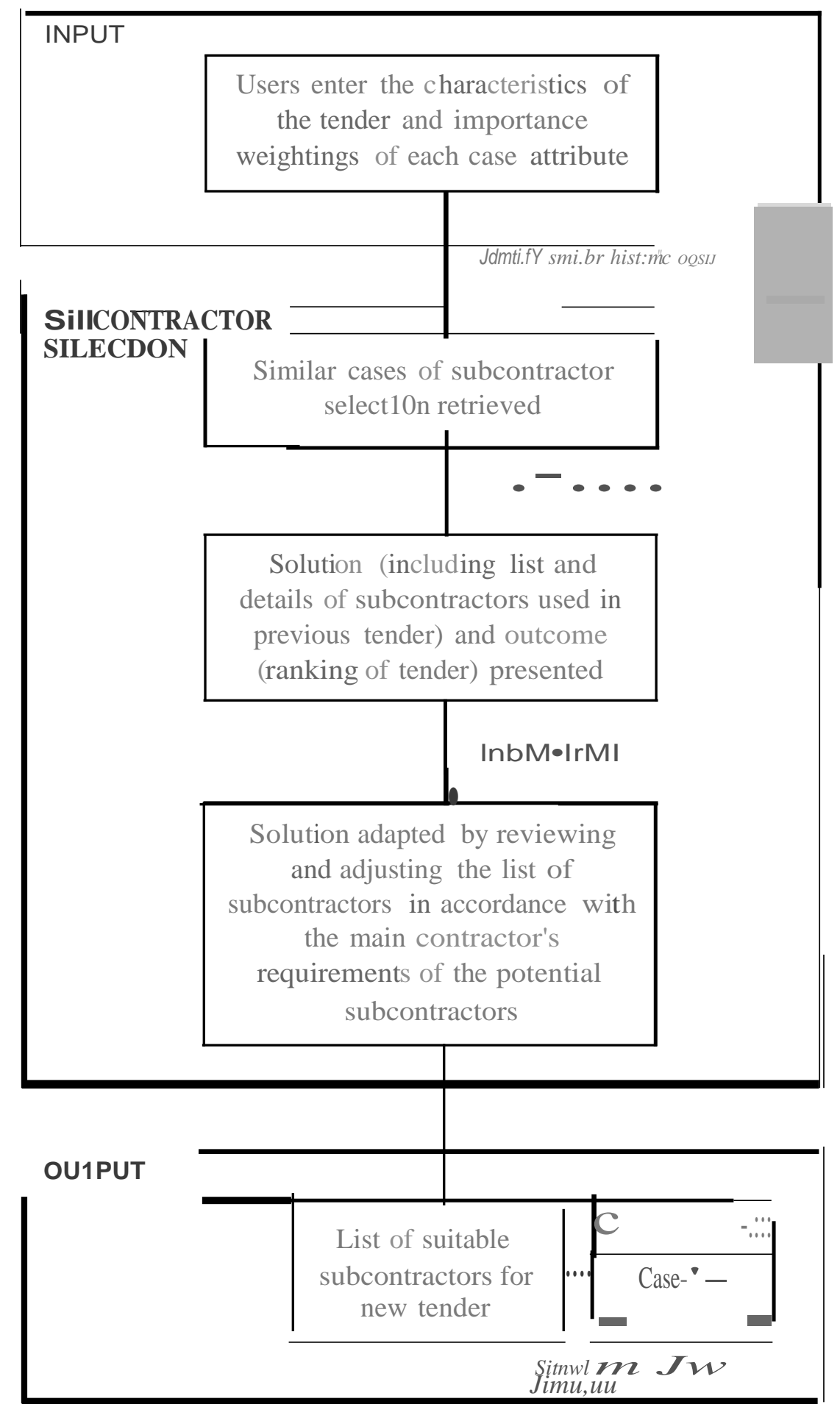

Figure 2: Conceptual framework of the case-based system for selecting subcontractors 
ARCHITECTURE OF THE CBR SUBCONTRACTOR SELECTION MODEL

To establish the suitability of CBR approaches in this domain, the conceptual framework described above was developed into a CBR prototype using ART"EnterpriseTM version 10.

\section{CASE REPRESENTATION}

A robust CBR system is largely dependent on a clear representation of constituent cases and an appropriate structure for describing their contents (Aamodt and Plaza, 1994). CASSS comprises three main constituents: problem, solution and outcome (Table 2).

\begin{tabular}{|c|c|c|}
\hline Case Attributes & Values & Characteristics \\
\hline \multicolumn{3}{|l|}{ Problem Part } \\
\hline Project Category & $\begin{array}{l}\text { Administrative and civic; } \\
\text { educational; hospital; industrial; recreationd } \\
\text { residential; civil engineering; others }\end{array}$ & $\begin{array}{l}\text { Categorical data with no } \\
\text { implied logicalrelationship }\end{array}$ \\
\hline Construction Type & $\begin{array}{l}\text { New construction; refurbishment; combination } \\
\text { of both }\end{array}$ & $\begin{array}{l}\text { Categorical data with no } \\
\text { implied logical relationship }\end{array}$ \\
\hline Size & $\begin{array}{l}<\$ 0.3 \mathrm{M} ; \quad \$ 0.3 \mathrm{M}-\$ 0.5 \mathrm{M} ; \quad \$ 0.5 \mathrm{M}-\$ 3 \mathrm{M} ; \quad \$ 3 \mathrm{M}- \\
\$ 20 \mathrm{M} ;>\$ 20 \mathrm{M}\end{array}$ & Quantitatively measurable \\
\hline Location & $\begin{array}{l}\text { Sydney; Wollongong and Illawara region; } \\
\text { Newcastle and Hunter valley region; Mid North } \\
\text { Coast; North Coast; North West NSW; South } \\
\text { West NSW }\end{array}$ & $\begin{array}{l}\text { Categorical data with no } \\
\text { implied logical relationship }\end{array}$ \\
\hline Complexity & High, medium, low & $\begin{array}{l}\text { Categorical data with } \\
\text { implied logical relationship }\end{array}$ \\
\hline Procurement Type & $\begin{array}{l}\text { Construct only; Design and construct; } \\
\text { Construction Management; Management } \\
\text { Contracting }\end{array}$ & $\begin{array}{l}\text { Categorical data with no } \\
\text { implied Iogical relationship }\end{array}$ \\
\hline \multicolumn{3}{|l|}{ Solution Part } \\
\hline Project Name & Name of Tender & Text \\
\hline Date Submitted & Date & Date \\
\hline $\begin{array}{l}\text { List of } \\
\text { Subcontractors } \\
\text { Used }\end{array}$ & $\begin{array}{l}\text { Details of each subcontractor for each category } \\
\text { including contract details, areas of operation, } \\
\text { experience in certain type of works, track record } \\
\text { of competitive pricing, track record of } \\
\text { performance during construction, financial } \\
\text { stability and record of current disputes with } \\
\text { main contractor }\end{array}$ & Various types \\
\hline \multicolumn{3}{|l|}{ Solution Part } \\
\hline $\begin{array}{l}\text { Ranking of Tender } \\
\text { Submitted }\end{array}$ & $1,2,3,4$, etc. & Quantitatively measurable \\
\hline
\end{tabular}

Table 2: Characteristics of case attributes 
The problem part is represented by a collection of tender similarity parameters. The solution part contains a list of subcontractors used in a past tender whereas the outcome provides feedback detailing the degree of success of the tender. The degree of success is measured by the client's ranking of the contractor's tender submi sion

prov1des a snapshot of case representation 1n CASSS. As the case attributes for CASSS contain both numerical and linguistic values various case representation schema were adopted to ensure case details were meaningfully encapsulated for future retrieval, comparison and reuse. Some of the schemas used are presented below.

Quantifiable data: To reduce computational effort and time, ranges were defined for quantifiable data. For instance, in CASSS, "project size" is divided into five ranges: (i) "less than \$0.3M"; (ii) "\$0.3M-\$0.5M"; (iii) - \$0.5 - \$3M"; (iv) "\$3M to \$20M"; and (v) over $\$ 20 M "$. The values of new and historic cases are considered equal if both are within the same range.

Categorical data with no implied logical relationship: Linguistic data is best captured through a precise and consistent categorical representation scheme, as this reduces the likelihood of misunderstanding and typing errors. Data of this type are codified as linguistic categories that best describe their cha cteristics

may Include such values as "commercial" "industrial', "residential' and so on. In addition, data with Boolean values (i.e. yes or no) belongs in this category too. As no logical relationship exists between the values, they can be regarded as discrete points where an exact match is required.

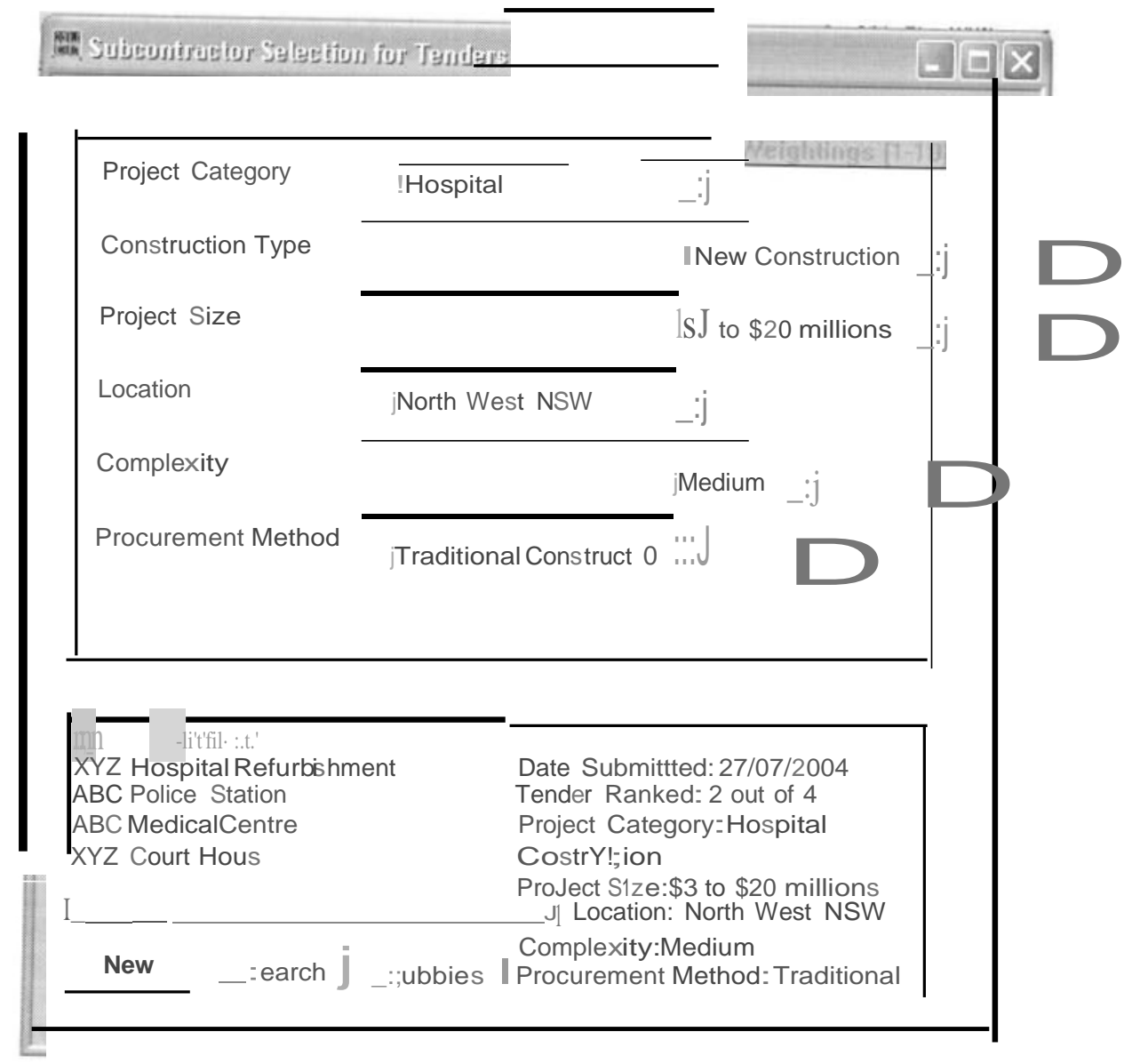

Figure 3: Case Representation in CASSS

Categorical data with an implied logical relationship: It is not uncommon to describe a concept using linguistic terms. For instance, "high", "medium" and "low" are 
used to describe various levels of market competitiveness, with the implication that "high" is better than "medium" and so on. The intrinsic relationship between these terms can be represented by a taxonomy tree. By defining the logical relationship through such a structure, the distance between two related values can be measured and a similarity score computed (Figure 4).

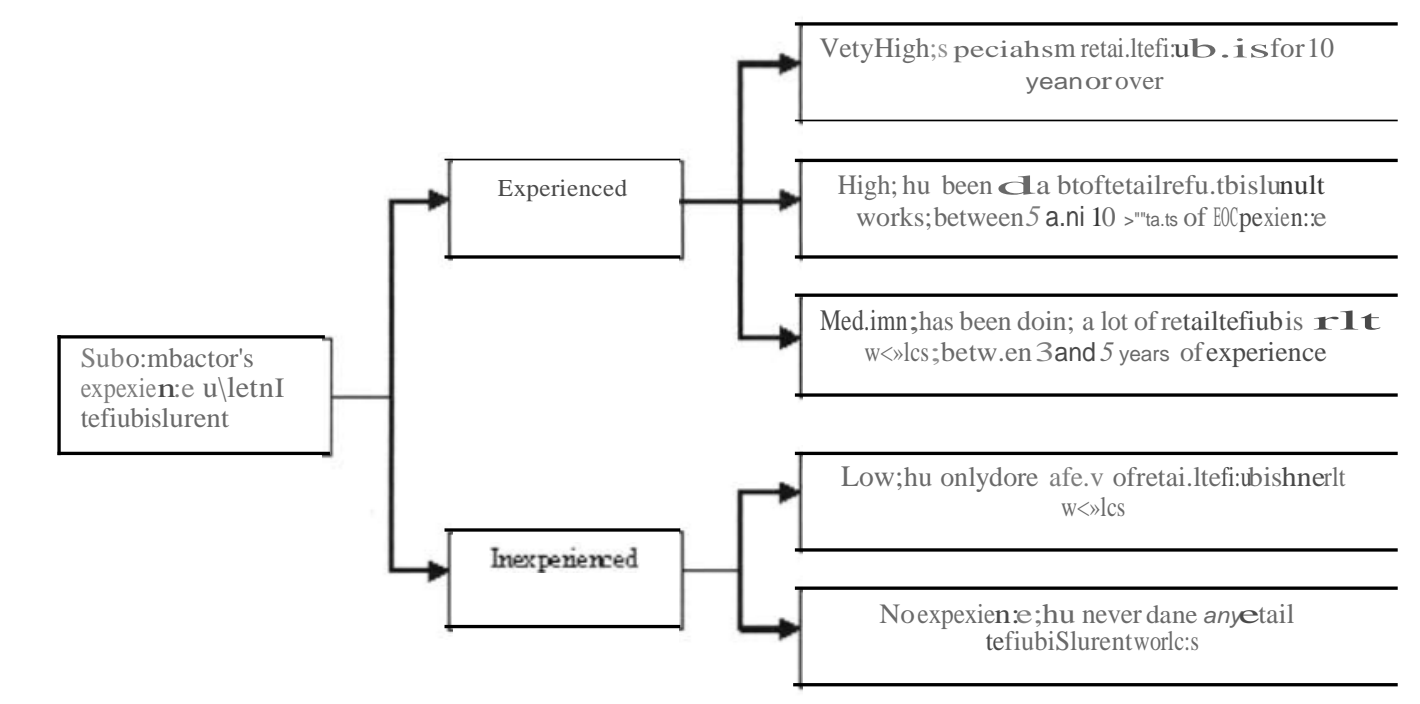

Figure 4: Taxonomy structure for reflecting the relationships of categorical data

In $\mathrm{ART}^{*}$ Enterprise $^{\mathrm{TM}}$ case attributes are represented as non-hierarchal. The major advantage of this organisation is that entire case libraries may be searched during the case matching and retrieval process. As a result, the accuracy of case retrievals is a function of how reliable the matching mechanisms are, whilst adding new cases to the case library is relatively cheap and easy compared to CBR systems which use hierarchical structures (Kolodner 1993).

\section{MATCHING AND RETRIEVAL}

Since flat organisational structures do not justify the use of inductive approaches, CASSS uses a nearest neighbor retrieval mechanism. Similar cases are retrieved from the case library on the basis of the global similarity value (total case score) which ranges from 0 to 100 ; with 100 representing an exact matching and 0 a total mismatch. The global similarity value is determined by the following formula:

Global similarity value $=L f\left(T ;, S_{1}\right) W_{1} \times 100$ fori $=1$ ton

where:

\author{
$T=$ target case \\ $\mathrm{S}=$ stored case \\ $n=$ number of attributes in each case \\ $i=$ an individual attribute from 1 to $n$ \\ $w=$ importance weightings of attribute $i$ \\ $f=$ local similarity between attribute $i$ in \\ cases Tand $\mathrm{S}$
}

The local similarity value (i.e. attribute score), on the other hand, ranges from 0 to 1. For attributes composed of categorical data with no implied logical relationship, the local similarity value is either 1 (when the two values are similar) or 0 . However, if there is an implied logical relationship between the data values or in the case of quantifiable data, the local similarity value is calculated in accordance with the positions where the data values of the two cases appear in the taxonomy tree. Thus the proximity of shared common index nodes indicates higher similarity values. Once similarity scores have been generated for all cases, they are ranked and the five cases with the highest similarity scores are presented for further consideration. 


\section{ADAPTATION}

A combination of different adaptation strategies was adopted for CASSS. For instance, if users are satisfied that a retrieved case closely resembles the current case (i.e. the tender being worked on), they can employ a null adaptation strategy by simply adopting the matching solution to the new case without any modification.

However, when the intrinsic characteristics of the two cases differ, modifications to the historic solutions might be desirable. Criticbased adaptation (Brown and Lewis, 1993) and parameterised adaptation (Schank et al, 1994) strategies are provided to help decision-makers arrive at more appropriate solutions.

In the solution part of each retrieved case, a list of subcontractors used in past tenders is presented to users. To facilitate detailed assessment of the suitability of the proposed subcontractors, the details of each subcontractor including area of operation, experience, performance, financial stability, etc. are provided (as shown in Figure 5).

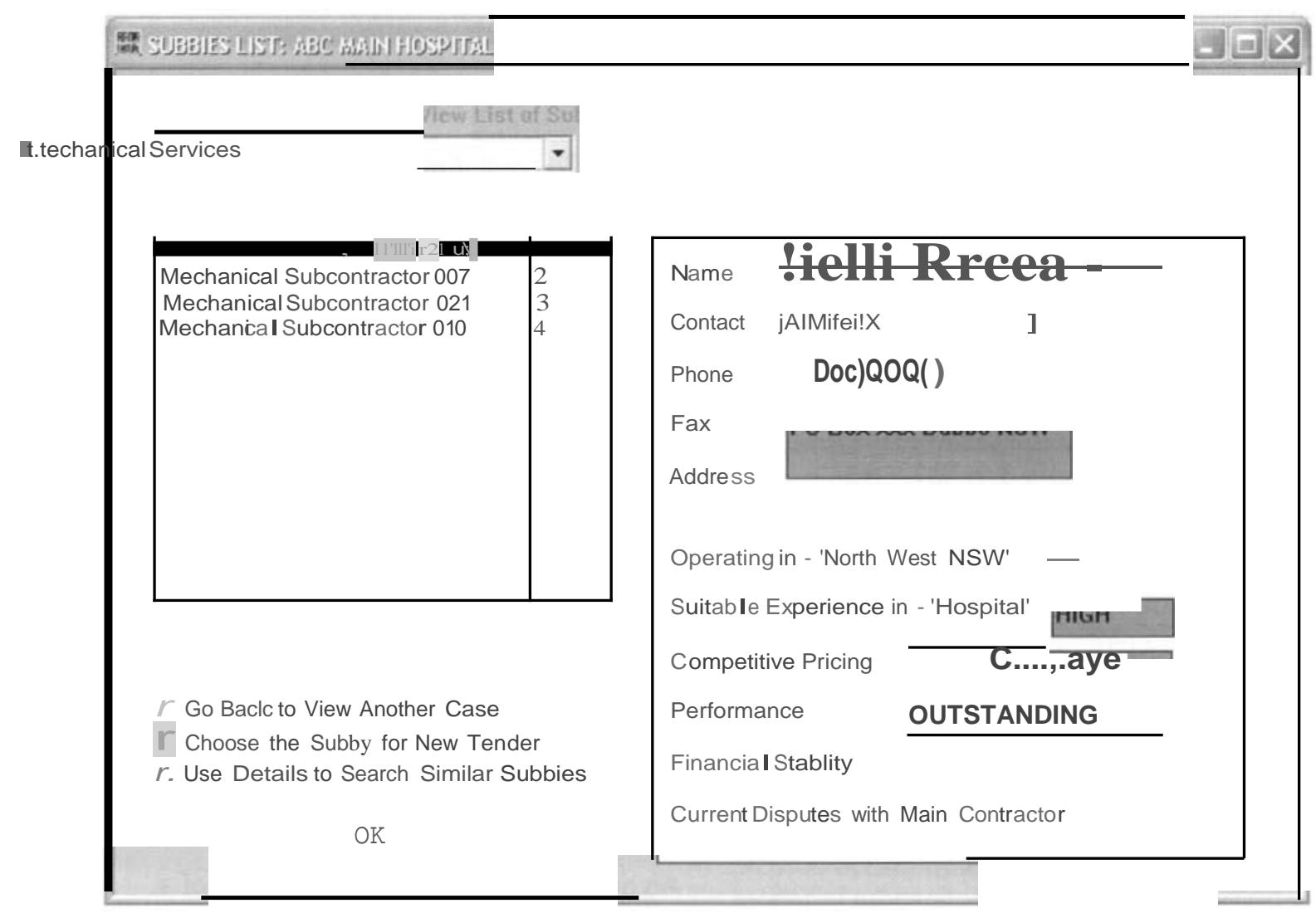

Figure 5: Subcontractor Details Screen in CASSS

If users are dissatisfied with the subcontractors proposed for a certain trade, they can search for ou-.er companies from the database of subcontractors using casebased reasoning. CASSS displays an adaptation screen to guide users through this process as shown in Figure 6. Users are required to enter characteristics of the required subcontractors and their importance weightings. Another CBR engine (which is incorporated into the adaptation mechanism of CASSS) allows users to search through the system's database of subcontractors for alternative subcontractors to the ones already proposed. Once users are satisfied with the list of subcontractors to be used in the new tender (case), a report of these subcontractors is available for the next stages of the tender process. 


\begin{tabular}{|c|c|c|}
\hline Operating in - 'North West NSW' & !Yes & :0...] \\
\hline Sutable Experience in - 'Hospital' & $\mathrm{HIGH}$ & '. \\
\hline Competitive Tender Pricing & !Always Competitive & 3110 \\
\hline Performance during Construction & joUTSTANDING & $3: 2$ \\
\hline Financial Stability & $\mathrm{jHIGH}$ & O:J Is \\
\hline Current Disputes with Main Contractor & jNo & $0:$.$] is$ \\
\hline
\end{tabular}

Mechanical Subcontractor 007 Mechani cal Subcontractor 010 Mechanical Subcontractor 021 Mechanical Subcontractor 015 Mechanical Subcontractor 027

Back to Previous Screen r.- dSulb Y. OK !" !!. Id

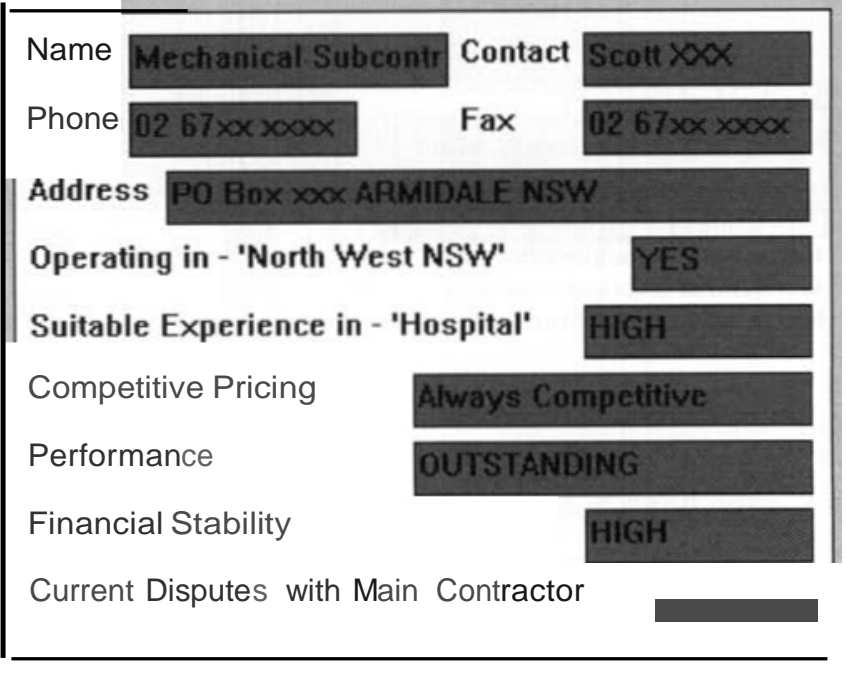

Figure 6: Critic-based adaptation using user's knowledge and CBR

\section{SYSTEM MAINTENANCE}

As the quality of the advice given by CASSS relies heavily on the quality of the information of past tenders, system maintenance (i.e. recording and updating of subcontractor information) is an important issue. As a feature of case-based reasoning, CASSS has the ability to record information of every new tender case and automatically update its database (i.e. the case base of tendered projects).

Furthermore, the system case base is also designed to link with the main database of subcontractors that is normally kept in a construction company. The system case base will automatically be updated if there is any change in the subcontractor information in the subcontractor database.

\section{SYSTEM PRACTICALITY}

An actual tender for the construction of a new hospital (with a value of approximately A $\$ 10 m)$ in New South Wales, Australia was used to demonstrate the practicality of CASSS. Some details of this tender are summarised in Table 3. 


\begin{tabular}{|l|l|}
\hline Tender Details & Details \\
\hline Project Category & Hospital \\
\hline Construction Type & New Construction \\
\hline Project Size & Approximately $\$ 8,000,000$ \\
\hline Location of Site & NSW North West \\
\hline Level of complexity of project & $\begin{array}{l}\text { A simple structure including slab on ground, light weight steel } \\
\text { frame, metal roof and external cladding. Services include } \\
\text { electrical, security, data, nurse call, ducted air conditioning, } \\
\text { water, sewer, stormwater, etc. }\end{array}$ \\
\hline Procurement method & Traditional Construct Only \\
\hline
\end{tabular}

Table 3: Details of test tender case

A total of 40 historic construction tenders were collected to train the CASSS model. A set of tender similarity parameters and their importance weightings were identified in accordance with the characteristics of the construction project, the external environment and the main contractor's expectation of potential subcontractors. CASSS then recommended a list of subcontractors for the tender ${ }^{1}$.

To determine whether the solution generated by the model was comparable to that produced by domain experts, four independent, experienced construction estimators with extensive local knowledge of subcontractors in the area were invited to assess the subcontractors chosen by CASSS.

As can be seen from the table above, there is generally an unequivocal agreement between the domain experts and CASSS. It is also noteworthy that the list of subcontractors selected by CASSS was quite similar to that prepared by the actual estimator of this particuiar tender, and that the estimator's tender was successful.

\section{CONCLUSION}

This paper has presented a novel way for selecting subcontractors for construction tender projects using CBR. Since CBR is an experience-based approach, the lessons learned in previous cases can be made available to estimators to provide them with an early indication of the likely future outcomes of a tender.

Based on the information collected from experts, a conceptual framework for a casebased system for selecting subcontractors at tender time was devised. The framework was subsequently developed into a computer prototype using a CBR shell $A R T^{\star}$ Enterprise. The prototype, using trial data, has demonstrated that CBR can provide appropriate recommendations for the tender of a hospital. However, in order for CASSS to be fully functional, further verification and validation of the system are needed.

${ }^{1}$ The issue of confidentiality prevented the authors from publishing details of these subcontractors 


\begin{tabular}{|c|c|c|c|c|c|}
\hline $\begin{array}{l}\text { Subcontractor } \\
\text { Category }\end{array}$ & $\begin{array}{c}\text { CASSS } \\
\text { Recommend } \\
\text { ations }\end{array}$ & Expert 1 & Expert 2 & Expert3 & Expert4 \\
\hline Excavation & 3 subbies & Agreed & Agreed & Agreed & Agreed \\
\hline Concrete & 3 subbies & Agreed & Agreed & Agreed & Agreed \\
\hline Structural Steel & 3 subbies & Agreed & $\begin{array}{l}\text { Added } \\
\text { another } \\
\text { subby }\end{array}$ & Agreed & Agreed \\
\hline Bricklayer & 2 subbies & Agreed & Agreed & Agreed & Agreed \\
\hline $\begin{array}{l}\text { Metal Roofing \& } \\
\text { Cladding }\end{array}$ & 3 subbies & Agreed & $\begin{array}{l}\text { Added } \\
\text { another } \\
\text { subby }\end{array}$ & Agreed & Agreed \\
\hline $\begin{array}{l}\text { Aluminum Windows \& } \\
\text { Doors }\end{array}$ & 4 subbies & Agreed & Agreed & Agreed & Agreed \\
\hline Doors \& Frames & 3 subbies & Agreed & Agreed & Agreed & Agreed \\
\hline Agreed Gyprocker & 3 subbies & Agreed & Agreed & Agreed & Agreed \\
\hline Carpet \& Vinyl & 3 subbies & Agreed & Agreed & Agreed & Agreed \\
\hline Tiling \& Waterproofing & 2 subbies & Agreed & Agreed & Agreed & Agreed \\
\hline Painting & 3 subbies & Agreed & Agreed & $\begin{array}{l}\text { Added } \\
\text { another } \\
\text { subby }\end{array}$ & Agreed \\
\hline Metalworks & 2 subbies & Agreed & Agreed & Agreed & Agreed \\
\hline Electrical Services & 3 subbies & Agreed & Agreed & Agreed & $\begin{array}{l}\text { Added } \\
\text { another } \\
\text { subby }\end{array}$ \\
\hline Mechanical Services & 3 subbies & Agreed & Agreed & Agreed & $\begin{array}{l}\text { Replace one } \\
\text { subby }\end{array}$ \\
\hline Hydraulic Services & 3 subbies & Agreed & Agreed & Agreed & Agreed \\
\hline Medical Gas Services & 3 subbies & Agreed & Agreed & Agreed & Agreed \\
\hline Fire Services & 2 subbies & Agreed & Agreed & Agreed & Agreed \\
\hline
\end{tabular}

Table 4: Results of system reliability test

\section{REFERENCES}

Aamodt, A. and Plaza, E. (1994). Case based reasoning: foundational issues, methodological vari ations and system approaches, Artificial Intelligence Communication, No. 7, 39-59.
Barletta, R. (1991). An introduction to casebased reasoning, Al Expert, 43-49.

Brown, S. J. and Lewis, L. M. (1993). A case-based reasoning solution to the problem of redundant resolutions of nonconformances in large-scale manufacturing, Innovative Applications of 
Artfficiallntelligence 3, eds. R. Smith \& C. Scott, AAAI Press, 121-133.

Kolodner, J. L. (1993). Case Based Reasoning, San Mateo, Morgan Kaufmann Publishers, CA.

Schank, R. C., Kass, A., and Riesbeck, C. K. (1994). Inside Case-Based Reasoning,

Erlbaum Associates, Hillsdale, N.J.

Shash, A. A. (1998). Bidding Practices of Subcontractors in Colorado, Journal of Construction Engineering and Management May/June 1998, 219-225.

Tam, E. (2003). STAT-USA Market Research Reports, U.S. \& Foreign Commercial Service and U.S. Department of State, 2003.

Tang, H. \{2001). Construct for excellence, report of the construction industry review committee, January 2001. The Printing Department, HKSAR. 